\title{
Endovascular Stent Treatment for Symptomatic Benign Iliofemoral Venous Occlusive Disease: Long-Term Results 1987-2009
}

\author{
A. Gutzeit $\cdot$ Ch. L. Zollikofer $\cdot$ M. Dettling-Pizzolato • \\ N. Graf $\cdot$ J. Largiadèr $\cdot$ C. A. Binkert
}

Received: 12 April 2010/Accepted: 4 June 2010/Published online: 1 July 2010

(C) The Author(s) 2010. This article is published with open access at Springerlink.com

\begin{abstract}
Venous stenting has been shown to effectively treat iliofemoral venous obstruction with good short- and mid-term results. The aim of this study was to investigate long-term clinical outcome and stent patency. Twenty patients were treated with venous stenting for benign disease at our institution between 1987 and 2005. Fifteen of 20 patients ( 15 female, mean age at time of stent implantation 38 years [range 18-66]) returned for a clinical visit, a plain X-ray of the stent, and a Duplex ultrasound. Four patients were lost to follow-up, and one patient died 277 months after stent placement although a good clinical result was documented 267 months after stent placement. Mean follow-up after stent placement was 167.8 months (13.9 years) (range 71 (6 years) to 267 months [22 years]). No patient needed an additional venous intervention after
\end{abstract}

\author{
A. Gutzeit $(\bowtie) \cdot$ Ch. L. Zollikofer · M. Dettling-Pizzolato · \\ C. A. Binkert \\ Department of Radiology, Cantonal Hospital Winterthur, \\ Brauerstrasse 15, 8401 Winterthur, Switzerland \\ e-mail: andreas.gutzeit@ksw.ch \\ Ch. L. Zollikofer \\ e-mail: Christoph.Zollikofer@ksb.ch \\ M. Dettling-Pizzolato \\ e-mail: Mira.Dettling@ksw.ch \\ C. A. Binkert \\ e-mail: christoph.binkert@ksw.ch \\ N. Graf \\ Clinical Trials Center, Center for Clinical Research, University \\ Hospital of Zurich, 8091 Zurich, Switzerland \\ e-mail: nicole.graf@usz.ch \\ J. Largiadèr \\ Department of Surgery, Klinik Im Park, 8027 Zurich, \\ Switzerland \\ e-mail: jon.largiader@gefaesschirurgie-zuerich.ch
}

stent implantation. No significant difference between the circumference of the thigh on the stented side (mean $55.1 \mathrm{~cm}$ [range 47.0-70.0]) compared with the contralateral thigh (mean $54.9 \mathrm{~cm}$ [range 47.0-70.0]) $(p=0.684)$ was seen. There was a nonsignificant trend toward higher flow velocities within the stent (mean $30.8 \mathrm{~cm} / \mathrm{s}$ [range 10.0-48.0]) and the corresponding vein segment on the contralateral side (mean $25.2 \mathrm{~cm} / \mathrm{s}$ [range 12.0-47.0]) $(p=0.065)$. Stent integrity was confirmed in 14 of 15 cases. Only one stent showed a fracture, as documented on $\mathrm{x}$-ray, without any impairment of flow. Venous stenting using Wallstents showed excellent long-term clinical outcome and primary patency rate.

Keywords Iliofemoral venous stent .

Benign venous stenosis $\cdot$ Long-term result

\section{Introduction}

Benign iliofemoral venous occlusion is often difficult to treat. The main goal is to improve patient quality of life and prevent chronic venous insufficiency (CVI), which may lead to an inability to work [1].

In the past, different surgical techniques involving venous bypass were used in cases of iliocaval venous obstruction [2-4]. The main problem with bypass surgery is its invasiveness and associated complications. The reported outcomes are rather poor, with patency rates between 54 and $84 \%$. Therefore, this therapy option is rarely used today [5].

In 1985, the first use of a self-expanding stent was described in the venous system of a dog [6]. Soon afterward the first studies in humans were published [7-9]. Good short- and mid-term patency rates were reported in 
these publications; however, the question of long-term clinical outcome and stent patency remained unanswered. The aim of the present study was to investigate clinical outcome as well as stent patency and integrity after followup $>5$ years.

\section{Materials and Methods}

The study was approved by our Institutional Review Board. Written informed consent was obtained from all patients.

\section{Patients}

From January 1987 to October 2005, 20 patients were admitted to our department for endovenous treatment of benign iliofemoral stenosis or occlusion. Five patients were excluded from further analysis. Four of these five patients were lost to follow-up. One patient died 277 months (23 years) after common iliac vein stent placement from a cause unrelated to the venous stent. For this patient, the last clinical visit 267 months (22 years) after stent placement showed a good clinical outcome after iliac vein stenting with no leg swelling. Fifteen patients (all female; mean age at time of stent implantation 38 years [range 18-66]) were included in the study. The etiology of obstruction was iatrogenic stenosis of an iliofemoral vein in four cases (patients no. 1, 2, 6, and 11) and stenosis of a venous interposition graft of the superficial femoral (patient no. 12) and the common femoral veins (patient 14). Six patients were treated with stents after thrombectomy for pelvic vein thrombosis caused by May-Thurner syndrome (patients no. $3,7,8,9,10$, and 15). Two patients were stented after recanalization of a chronic postthrombotic obstruction of the common and/or external iliac veins (patient no. 5 and 13). One patient was treated with common iliac vein stent during treatment of an acute four-level thrombosis (patient no. 4). Details concerning patient data are listed in Table 1.

\section{Venous Intervention}

The procedure was performed in the interventional suite using either an ipsilateral retrograde percutaneous femoral vein access in cases of a common or external iliac vein obstruction or a crossover technique in cases of a common femoral vein stenosis. In one patient with a long-standing occlusion of the common and external iliac veins, a transjugular approach had to be used (patient no. 5). In all patients, self-expanding Wallstents (Boston Scientific, Natick, MA) were used (details of stent dimensions are listed in Table 1). We did not use other stent types. In the cases of iatrogenic or postoperative stenoses as well as chronic obstruction, a probatory test balloon angioplasty was performed to evaluate adequate stent size. The Wallstent was oversized by at least $1 \mathrm{~mm}$. In cases of insufficient spontaneous self-expansion after placement, the stent was dilated to the estimated diameter of the treated vein. During the procedure, $5000 \mathrm{U}$ heparin were administrated intravenously. After stent placement all patients were treated routinely with warfarin for 6 months. Patients no. 4 and 13 (Table 1) had a factor V Leiden mutation, which was treated with long-term therapy during the entire observation period.

\section{Follow-Up}

Follow-up was conducted from October 2009 to November 2009. Follow-up included a clinical examination with measurement of leg circumferences, Duplex ultrasound, and x-ray of the stent. Fourteen of 15 follow-up examinations were performed at the institution where the stents were placed. In one case (patient no. 14), the follow-up examination was performed in another hospital overseas.

\section{Clinical Investigation}

The patients were questioned for any intervention or surgery concerning their veins after stent placement. Signs of venous insufficiency, including varicosities and ulcers were recorded. Maximum circumferences of the thighs and calves were measured.

\section{Duplex Ultrasound}

The patients were examined using a state-of-the-art ultrasound scanner (Acuson Sequoia 512; Siemens, Munich, Germany). 4- and 8-MHz probes were used. The presence or absence of venous flow through the stent was investigated. In addition, maximum velocities within the stent and the contralateral untreated vein were recorded. Furthermore, it was documented if there was venous reflux under Valsalva maneuver.

\section{X-Ray}

Plain X-ray of the stent area was performed in anteroposterior view. In 14 patients, a film of the pelvis was obtained, and a film of the thigh was taken in one patient (patient no. 14). X-rays were analyzed for stent fractures on a PACS system (Impax 4.2, Agfa) that allowed magnified and inverted views.

Statistical Analysis

Statistical analyses were performed using the statistical program SPSS version 17 (SPSS version 17.0.1; SPSS, 


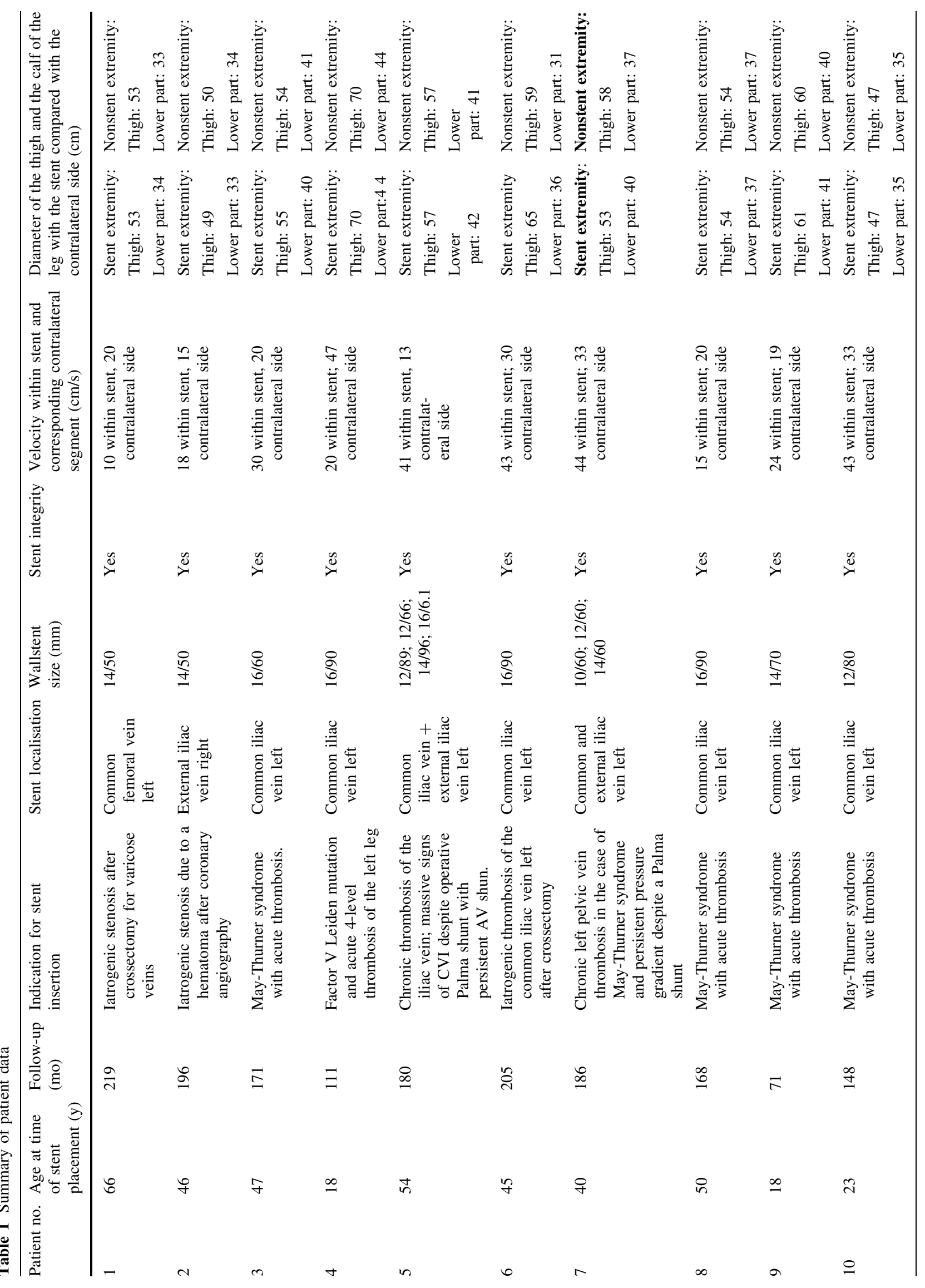




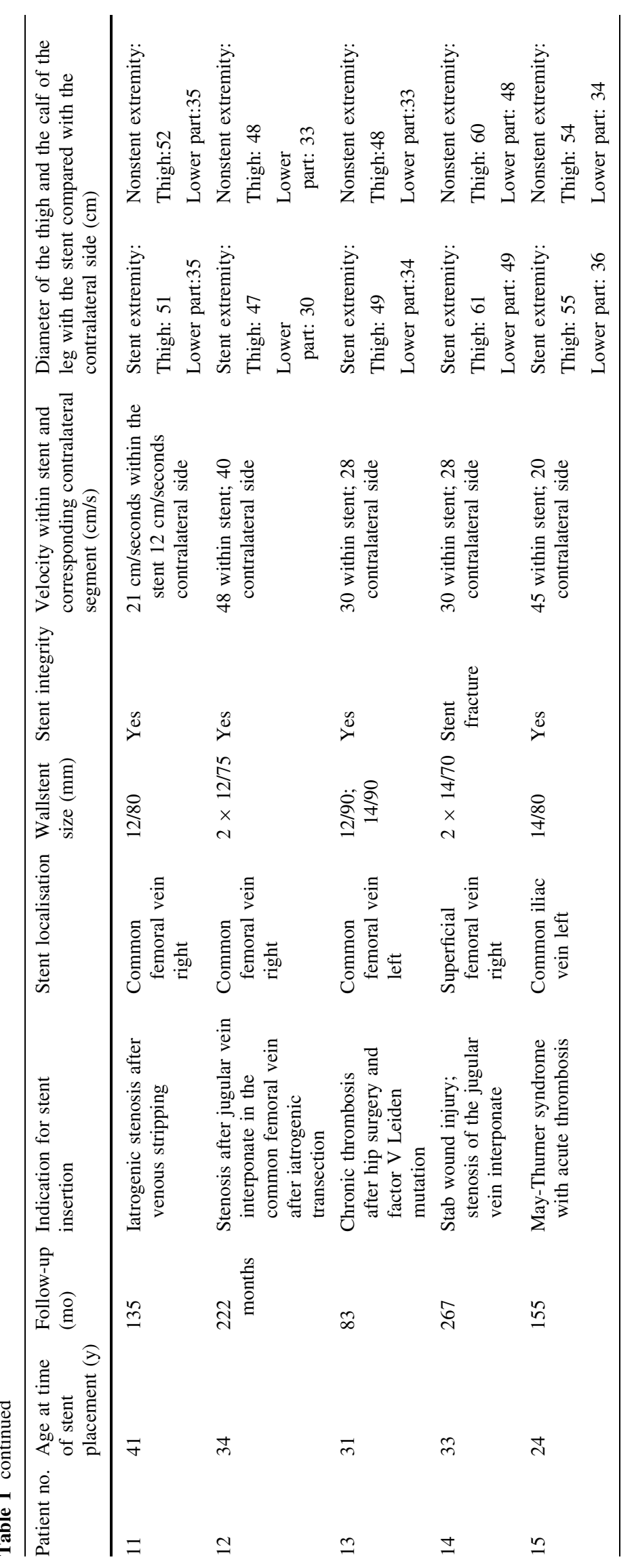


Chicago, IL). The data were analyzed, and a mean of the circumferences of the treated and nontreated legs, as well as flow measurements within the stent, were evaluated. Wilcoxon signed-rank test was used for comparisons within paired samples.

\section{Results}

\section{Clinical Outcome}

Mean follow-up after stent placement was 167.8 months (13.9 years) (range 71-267 [6 to 22 years]). No patient needed any additional intervention after stent implantation.

Two patients showed mild varicosis (patients no. 3 and 5 ), which had existed before venous stenting. In one patient, severe venous insufficiency (patient no. 6) with chronic venous ulcers was detected. This patient had severe varicosity documented before the intervention.

No significant difference $(p=0.684)$ between the circumference of the thigh on the stented side (mean $55.1 \mathrm{~cm}$ [range 47.0-70.0]) and the contralateral thigh (mean $54.9 \mathrm{~cm}$ [range 47.0-70.0]) was found. There was a nonsignificant tendency toward a greater circumference of the calf on the treated side (mean $37.7 \mathrm{~cm}$ [range 30.0-49.0]) compared with the nontreated side (mean $37.1 \mathrm{~cm}$ [range $31.0-48.0])(p=0.191)$.

\section{Duplex Ultrasound}

All stents were patent and had respiratory variation of flow. No stenosis or occlusion within the stent was seen. There was a nonsignificant trend of higher flow velocities within the stent compared with the corresponding segment of the contralateral side $(p=0.065)$. The median maximal velocity within the stent was $30.0 \mathrm{~cm} / \mathrm{s}$ (range 10 48 ), and the median maximal velocity of the contralataral side was $20.0 \mathrm{~cm} / \mathrm{s}$ (range 12-47). No patient showed venous reflux under the Valsalva maneuver within the stented segment.

\section{X-Ray}

Stent integrity, with normal stent morphology, was documented in 14 of 15 cases (Fig. 1). One stent showed a single stent fracture (patient no. 14). We guess that the reason for this fracture was a calcified hematoma adjacent to the stent, which resulted in chronic mechanical stress (Fig. 2A-F). It is remarkable that even stents placed in the common femoral vein directly over the hip joint (patients no. 1 and 11 through 13) showed no fracture after 83 to 222 months later (Fig. 3A, B).

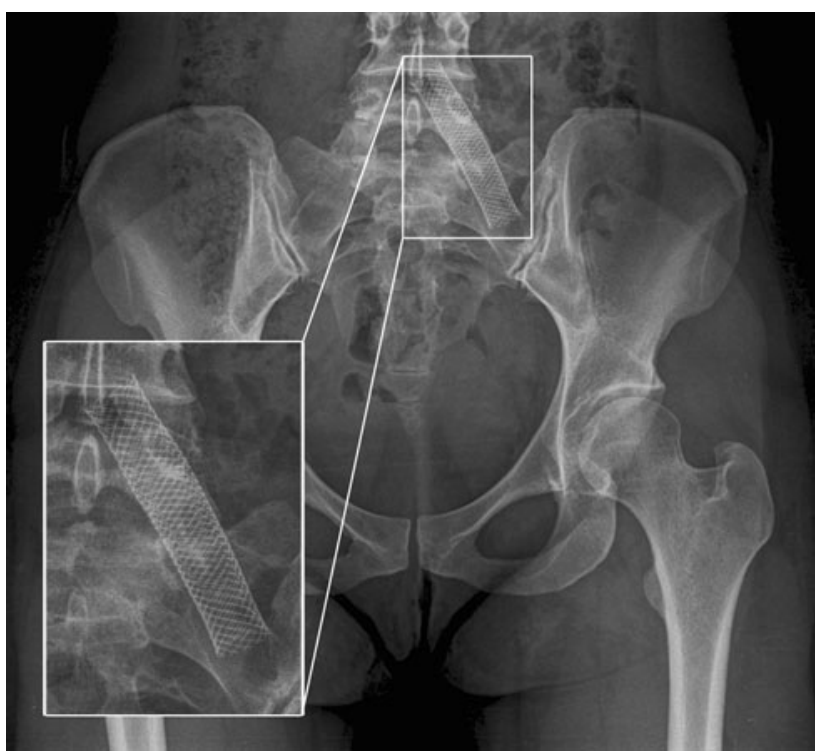

Fig. 1 Shows X-ray of the pelvis, including a magnified view demonstrating the integrity of the stent in the left common iliac vein 13 years after placement for acute thrombosis due to a May-Thurner syndrome

\section{Discussion}

Our data suggest that stenting of benign iliofemoral venous obstruction has a good long-term clinical outcome with excellent stent patency. After a mean follow-up of 167.8 months (13.9 years), no additional venous intervention was needed in any patient. There was no significant leg swelling of the stented extremity compared with the contralateral side.

Since its introduction in the mid-1980 s, venous stenting has become a widely accepted treatment option [10-14]. Venous stenting has replaced surgical techniques, such as the Palma operation or the axial bypass technique for venous obstruction [15]. Not only is surgery more invasive than stenting, it also shows low patency rates between $44 \%$ and $85 \%$ [16].

Few reports about the mid- and long-term results after stenting of benign iliocaval obstructions [17-22] have shown patency rates approaching $100 \%$ without any stent fractures or other stent-related complications.

Our study focused on long-term outcomes $>5$ years. The results confirm excellent long-term result, with a patency rate of $100 \%$, which corresponds to the good clinical outcome as measured by the lack of leg swelling.

Stent integrity has generally not been assessed in the venous system in the published literature [17-22] compared with the arterial system, in which stent fractures are of concern, particularly in the lower extremity [23, 24]. We encountered only one stent fracture $(6.7 \%)$ in a special situation, i.e., the stent was placed in the superficial 

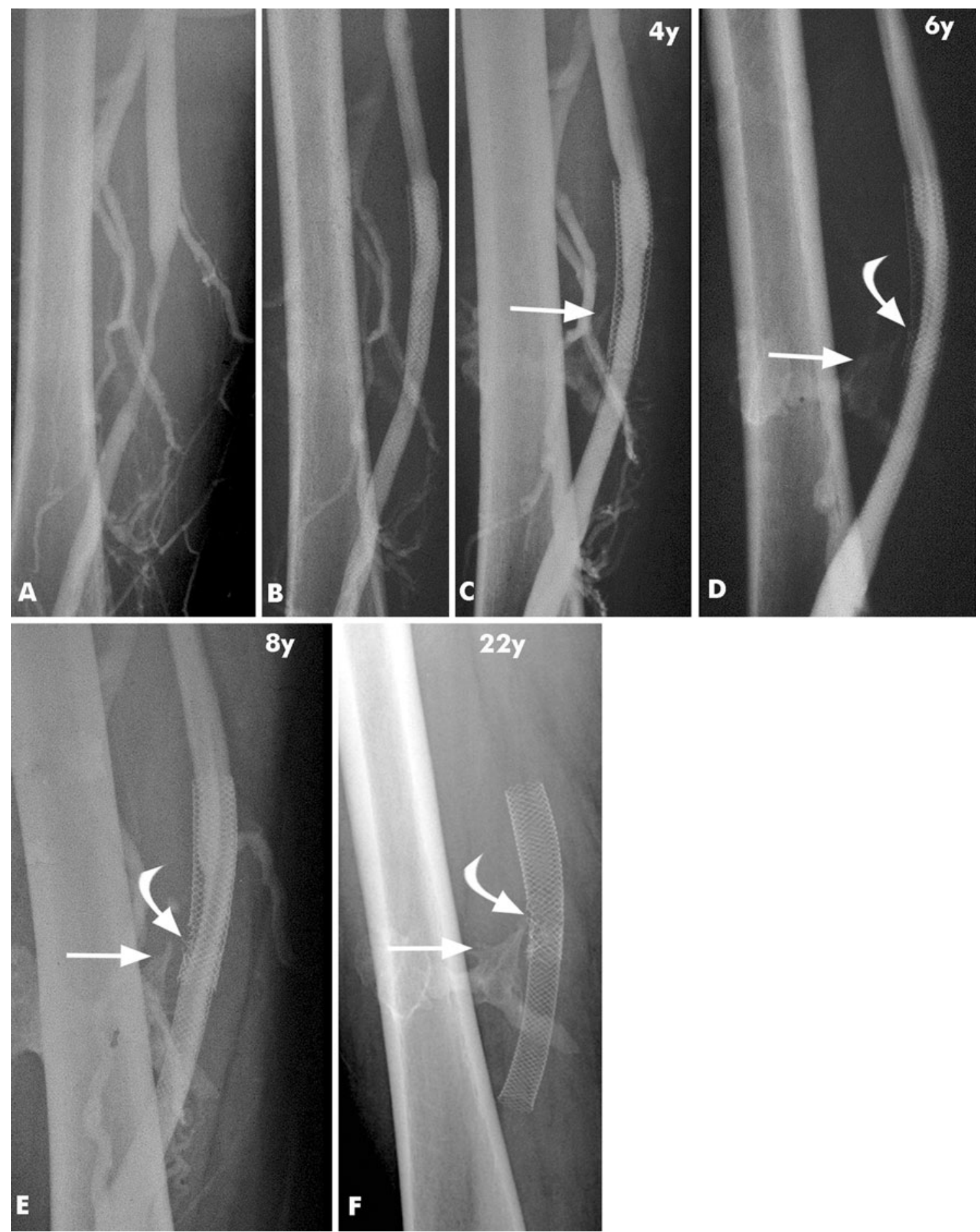

Fig. 2 Serial venograms during a follow-up period of 22 years (patient no. 14) after a stab wound injury of the right superficial femoral vein, which was treated with a venous interposition graft, resulting in stenosis of the femoral vein. A Venogram shows severe stenosis corresponding to the venous interposition graft. B Venogram taken after placement of two $14 \times 70-\mathrm{mm}$ Wallstents in the superficial femoral vein. C Venogram taken 4 years later shows new soft-tissue calcification adjacent to the patent stent (arrow),

which was interpreted as a calcified hematoma or myositis ossificans. The stent is intact at follow-up of 6, 8, and 22 years. D, F A stent fracture can be noticed (curved arrow), which remained mostly unchanged over the years, with no signs of flow impairment or clinical signs of leg swelling. The likely cause of the stent fracture can be identified as the pointed part of the calcification (arrow) interfering with the stent 
Fig. 3 A X-ray of the right hip in a bent position after placement of two $12 \times 75-\mathrm{mm}$ Wallstents in the common femoral vein (patient no. 12) shows good adaption of the Wallstent to the curving course of the common femoral vein, with no signs of kinking or damage to the stent The upper and lower edges of the stent are marked with arrows. B X-ray of the hip of the same patient 18.5 years after placement shows that the Wallstent remained intact
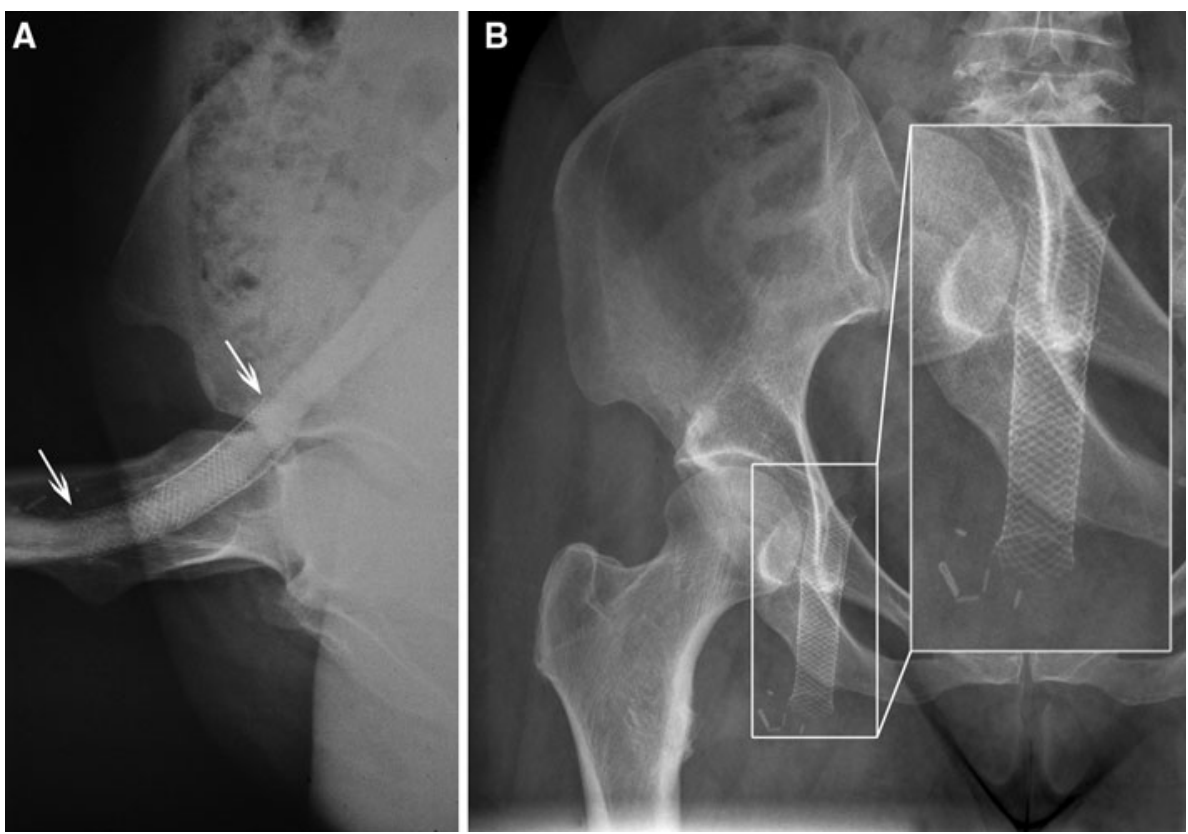

femoral vein (patient no. 14). During follow-up, soft-tissue calcifications developed lateral to the stent, which led to focal stent fracture after 6 years. The stent remained patent without any impairment of flow, despite the fracture, during a follow-up of 22 years.

Interestingly, no fractures were seen in the four stents placed in the common femoral vein across the hip joint. One patient (patient no. 15) with a common iliac stent had a normal pregnancy without any damage to the stent.

In the present study, patients were treated with warfarin for 6 months. Thereafter, no further anticoagulation was given routinely. Because no thrombosis occurred during our study, long-term anticoagulation did not seem necessary. The ability to stop anticoagulation is helpful because long-term anticoagulation during a period of years has its own risks [25].

Our study has several limitations. First, we only include a small study group, especially in the age group $<50$ years. Therefore, the long-term results should be interpreted with caution. The second limitation is the use a single device type (Wallstent), and the third limitation is the variety of underlying causes for venous obstruction.

In conclusion, venous stenting with Wallstents showed an excellent patency rate with good clinical outcomes between 71 months (6 years) and 267 months (22 years).

Conflict of Interest Statement The authors declare that they have no conflict of interest.

Open Access This article is distributed under the terms of the Creative Commons Attribution Noncommercial License which permits any noncommercial use, distribution, and reproduction in any medium, provided the original author(s) and source are credited.

\section{References}

1. Meissner MH, Eklof B, Smith PC et al (2007) Secondary chronic venous disorders. J Vasc Surg 46(Suppl S):68S-83S

2. Alimi YS, DiMauro P, Fabre D, Juhan C (1997) Iliac vein reconstructions to treat acute and chronic venous occlusive disease. J Vasc Surg 25:673-681

3. Jost CJ, Gloviczki P, Cherry KJ Jr et al (2001) Surgical reconstruction of iliofemoral veins and the inferior vena cava for nonmalignant occlusive disease. J Vasc Surg 33:320-327

4. Alimi YS, Juhan C (1998) New trends in the surgical and endovascular reconstructions of large veins for nonmalignant chronic venous occlusive disease. Curr Opin Cardiol 13:375383

5. Halliday P, Harris J, May J (1985) Femoro-femoral crossover grafts (Palma operation): a long-term follow up study. In: Bergan KK, Yao JST (eds) Surgery of the veins. Grune \& Stratton, Orlando, pp 241-254

6. Wright KC, Wallace S, Charnsangavej C, Carrasco CH, Gianturco C (1985) Percutaneous endovascular stents: an experimental evaluation. Radiology 156:69-72

7. Zollikofer CL, Largiader I, Bruhlmann WF, Uhlschmid GK, Marty AH (1988) Endovascular stenting of veins and grafts: Preliminary clinical experience. Radiology 167:707-712

8. Antonucci F, Salomonowitz E, Stuckmann G, Stiefel M, Largiadèr J, Zollikofer CL (1992) Placement of venous stents: clinical experience with a self-expanding prosthesis. Radiology 183:493497

9. Zollikofer CL, Antonucci F, Stuckmann G, Mattias P, Brühlmann WF, Salomonowitz EK (1992) Use of the Wallstent in the venous system including hemodialysis-related stenoses. Cardiovasc Intervent Radiol 15:334-341

10. Oguzkurt L, Tercan F, Ozkan U, Gulcan O (2008) Iliac vein compression syndrome: outcome of endovascular treatment with long-term follow-up. Eur J Radiol 68:487-492

11. Schwarzbach MH, Schumacher H, Böckler D et al (2005) Surgical thrombectomy followed by intraoperative endovascular reconstruction for symptomatic ilio-femoral venous thrombosis. Eur J Vasc Endovasc Surg 29:58-66 
12. Neglén P, Hollis KC, Olivier J, Raju S (2007) Stenting of the venous outflow in chronic venous disease: Long-term stent-related outcome, clinical, and hemodynamic result. J Vasc Surg 46:979-990

13. Carlson JW, Nazarian GK, Hartenbach E et al (1995) Management of pelvic venous stenosis with intravascular stainless steel stents. Gynecol Oncol 56:362-369

14. Ley EJ, Hood DB, Leke MA, Rao RK, Rowe VL, Weaver FA (2004) Endovascular management of iliac vein occlusive disease. Ann Vasc Surg 18:228-233

15. Palma EC, Esperon R (1959) Treatment of the post-thrombophlebitic syndrome by means of internal saphenous transplants. Bol Soc Cir Urug 30:115-125

16. Nicolaides AN, Allegra C, Bergan J et al (2008) Management of chronic venous disorders of the lower limbs: guidelines according to scientific evidence. Int Angiol 27:1-59

17. Kölbel T, Lindh M, Akesson M, Wassèlius J, Gottsäter A, Ivancev K (2009) Chronic iliac vein occlusion: midterm results of endovascular recanalization. J Endovasc Ther 16:483-491

18. Hartung O, Loundou AD, Barthelemy P, Arnoux D, Boufi M, Alimi YS (2009) Endovascular management of chronic disabling ilio-caval obstructive lesions: Long-term results. Eur J Vasc Endovasc Surg 38:118-124
19. Hartung O, Otero A, Boufi M et al (2005) Mid-term results of endovascular treatment for symptomatic chronic nonmalignant iliocaval venous occlusive disease. J Vasc Surg 42:1138-1144

20. Hartung O, Benmiloud F, Barthelemy P, Dubuc M, Boufi M, Alimi YS (2008) Late results of surgical venous thrombectomy with iliocaval stenting. J Vasc Surg 47:381-387

21. Wohlgemuth WA, Weber H, Loeprecht H, Tietze W, Bohndorf K (2000) PTA and stenting of benign venous stenoses in the pelvis: Long-term results. Cardiovasc Intervent Radiol 23:9-16

22. Nazir SA, Ganeshan A, Nazir S, Uberoi R (2009) Endovascular treatment options in the management of lower limb deep venous thrombosis. Cardiovasc Intervent Radiol 32:861-876

23. Boehm G, Gschwendtner M, Schillinger M (2009) Carotid stent fracture: diagnosis and management. Catheter Cardiovasc Interv $74: 273-277$

24. Schlager O, Dick P, Sabeti S et al (2005) Long-segment SFA stenting - the dark sides: in-stent restenosis, clinical deterioration, and stent fractures. J Endovasc Ther 12:676-684

25. Wells PS, Forgie MA, Simms M (2003) The outpatient bleeding risk index: validation of a tool for predicting bleeding rates in patients treated for deep venous thrombosis and pulmonary embolism. Arch Intern Med 163:917-920 